\title{
Electronic Journals in the Online Catalog: Selection and Bibliographic Control
}

\section{Pamela Simpson and Robert Seeds}

As the publishing of electronic journals increases, so does user demand for access to these items. Librarians are faced with the tasks of selecting, acquiring, and providing access to electronic journals. Principles of selection used for materials in other formats should be the foundation for selecting electronic journals as well, but selectors must also be aware of unique aspects of these items, such as licensing agreements and hardware or software required to use them. Acquiring and cataloging electronic journals poses challenges in processes that were created to process items housed in physical carriers. Cataloging of these journals requires decision making at several different levels; these decisions include choosing the number of records to be used and the content of those records. Procedures for ordering and cataloging electronic journals at the University Park Campus of the Pennsylvania State University Libraries are described. Successfully integrating electronic journals into the collection and the catalog requires close cooperation between selectors, reference librarians, and catalogers.

$\mathbf{T}_{1}$ he number of electronic journals being published continues to skyrocket. According to the Association of Research Libraries (ARL), in 1996 alone there was a $257 \%$ increase (ARL 1996). In the 7 th edition of the ARL Directory of Electronic Journals, Newsletters, and Discussion Lists, published in 1997, there are twice as many journals listed as there were in 1996. The proliferation of these new journals is occurring not only in the sciences (which make up 29\% of the total listings), but across all disciplines. Journals in the arts and humanities and the social sciences comprise $42 \%$ of the total listings (ARL 1998).

In a series of focus groups conducted by the Pennsylvania State University Libraries (PSUL), participants (faculty, staff, and students of all levels) "discussed investment in electronic resources in highly positive terms," "uniformly agreed that electronic resources are a good thing," "want more electronic resources -full-text in particular," and "want to be able to do more [with them] from their home or offices" (Avery 1996, 2).

The rapid growth in electronic publi-

Payela Simpson (p2s@psulias.psu.edu) is Serials and Electronic Resources Cataloging Librarian, the Pennsylvania State University, University Park, Pennsylvania. Robert SeEdS (rss@psulias.psu.edu) is Head of Mathematics Library, the Pennsylvania State University, University Park, Pennsylvania. Manuscript received October 14, 1997; accepted for publication January 28, 1998 
cations, together with user demands for better access to more online information, is pushing librarians to focus on these resources. How do we select which electronic titles to acquire for our libraries and then how do we handle their bibliographic control once we do? In this article, we describe the emerging model for selection, ordering, and bibliographic control of electronic journals at PSUL.

\section{BACKgROUND}

Penn State employs a highly dispersed model of selection. Almost all 52 librarians working at the University Park Campus have responsibility for one or more subject funds. Individual selectors participate in selection groups, including literature, humanities, social sciences, and sciences. These groups are led by experienced selectors and share responsibility for some general subject funds. The selection process is overseen by the coordinator for collection development.

In February 1996, the coordinator for collection development asked a group of librarians and staff to participate in a task force that was charged with developing procedures for ordering and cataloging electronic journals. The task force conducted its business via e-mail to avoid the difficulties of scheduling face-to-face meetings. Prior to the formation of this task force, the catalog included fewer than 50 records for Internet resources-mostly for U.S. and international government documents and for databases and reference works Penn State accessed through CIC (Committee on Institutional Cooperation) consortial purchases. However, several selectors were interested in ordering electronic journals through their individual subject accounts and we had no procedures in place for doing so. The selector for mathematics and computer science was particularly interested in access to four journals published by the American Mathematical Society. The task force conducted a pilot project by following the processing of these four journals and discussing the issues that arose as they were selected, acquired, cataloged, and linked on the PSUL Web page. The task force then produced a set of procedures (see figure 1).

\section{Procedures and Problems}

Since the completion of this pilot project, Penn State has placed orders for and cataloged approximately 135 additional electronic journals. Steps 1-3 of our process have worked smoothly. We have found, however, that problems sometimes occur with the confirmation of access in Step 4. Because no physical issues arrive, verifying that we have "received" an Internet resource can be difficult. Several publishers have failed to inform us that we have access, so we must keep a file of pending items and inquire repeatedly to determine whether the subscription has gone through. Conversely, we have on occasion received notification that our payment had been processed and our access was arranged, only to find that, in fact, we could not access the item.

Both acquisitions and cataloging processes have traditionally been built around the movement of physical volumes through physical space. It is difficult for both our procedures and our people to adapt to the change from tracking physical volumes to tracking access to an item via Internet. Physical volumes can be seen on trucks or desks, and it is obvious when they have moved from one person's area to another and clear when they have been placed on the public shelves. Orders and requests for cataloging for remotely accessed publications can get lost more easily, and staff must be diligent and persistent to track receipt and processing of these items.

We have not experienced any procedural difficulties with steps 5-6. At this time, all cataloging of electronic journals is done by Simpson. We anticipate, however, that in the near future the increase in workflow will warrant training at least one staff person to do copy cataloging of electronic journals. At that time, more detailed cataloging procedures will be required.

As for step 7 of our procedures, selectors make links on one or more of the 
General: The initiator of a Web-based subscription (usually the faculty selector) must know and understand the basic technical requirements of licensing Web access to an electronic journal. It doesn't matter whether the Web journal costs money or not. It matters if the Web journal requires a license for access. When licenses are required, some guarantee is normally offered to restrict access to licensed users. Currently, for straightfonward Web-based subscriptions, we prefer to filter by IP address. If the supplier of the Web journal is willing and able to filter by IP address, then the selector will follow the instructions below. If, for any reason, the supplier of the Web journal is unwiling or unable to filter by IP address, then the selector is directed to handle such subscriptions on a case-by-case basis with the Collection Development Coordinator.

Step 1 The selector identifies the desired electronic journal, contacts the supplier, and ascertains whether or not the supplier will filter licensed access by IP address.

Step 2 If the supplier will filter by IP address, the selector contacts the Acquisitions Team and provides all the pertinent information including title, cost and fund information (if payment is required), and the URL.

Step 3 The Acquisitions Team "acquires" the journal by providing the supplier with the necessary IP addresses and payment, if required.

Step 4 Upon confirmation of access, the Acquisitions Team contacts the Serials and Electronic Resources Cataloging Librarian and the Libraries' Internal Webmaster and provides them with all the pertinent information including title, URL, and name of the selector.

Step 5 The Serials and Electronic Resources Cataloging Librarian creates a bibliographic record in the catalog and the Libraries' Internal Webmaster makes the necessary links on the Staff or Faculty Web page.

Step 6 The Cataloging Librarian contacts the selector and confirms that the Web journal is cataloged and available.

Step 7 The selector is then responsible for adding or linking the Web journal to any pertinent public Web pages. Additionally, the selector is responsible for contacting Cataloging and the Libraries' Internal Webmaster when and if the title, URL, or other significant attributes of the product change.

Figure 1. Procedures for Ordering Electronic Journals at the Pennsylvania State University, University Park Campus.

PSUL Web pages as they see fit. Not enough time has passed to determine how effectively individual selectors will be able to monitor the Uniform Resource Locators (URLs) and titles of electronic journals. With the loss of the check-in function, we have lost the forced opportunity to examine each issue as it arrives. For print publications and for computer files acquired in a physical carrier, alert checkin staff catch changes in title or frequency, or the appearance of corporate bodies that require additional access points. While it is theoretically possible for check-in staff to begin monitoring the arrival of each issue of electronic journals, so far we have not deemed this a wise use of staff time. Some libraries use special software programs to check URLs, with varying results. It is foreseeable that better pro- grams will be developed for URL checking, or that standards such as the Persistent Uniform Resource Locators (PURL) or the Uniform Resource Name (URN) will solve the problem of changing locations of remote resources. It is unlikely, however, that there will be machine solutions for the need to monitor other changes in these journals, such as in content, file format, or title.

\section{Electronic Journal Selection}

The most obvious starting point for selection of electronic journals is to apply the same criteria a selector would utilize when choosing to initiate a print journal subscription. Qualitative measures include: whether the title is refereed; the reputation of the editorial board; the 
reputation of the publisher; and whether the articles are fitting, thorough, and well executed. Appropriateness indicators include: interest in the title at the institution, recommendations from constituents, user inquiries, and document delivery requests. Cost factors include: affordability, cost-benefit balance, and support requirements. If most of these questions are answered in the affirmative, then the selector will most likely subscribe to the publication.

Selectors must be wary of the novelty factor in this situation. Publishing via the Internet, especially the World Wide Web, is still so new that it is tempting for selectors to suspend normal judgement and rush into adding these resources to library collections, perhaps just to get experience with them and demonstrate innovation to their clientele. We must remember that even "free subscriptions" ultimately carry a price for the library, including cataloging, curating, maintaining, providing technical support, and educating users about a title.

Some titles that are available at no charge offer full-text articles, but many others offer only abstracts or tables of contents. In the latter case, online versions of abstracts and contents are often made available before the print versions, which makes them attractive to some users. However, while abstracts and tables of contents alone are useful for some researchers, these products often seem to function largely as promotions for the print version of those titles. In general, we have found that our users are better served by abstracting and indexing databases that provide such information in a more systematic fashion. For this reason, Penn State has chosen not to catalog electronic serials that include only abstracts or tables of contents, though a note and an electronic link can be added to the record for the print item informing users of the existence of the electronic item.

\section{Bibliographic Control}

As electronic journals are selected for a collection, questions of bibliographic con trol must be addressed. Library catalogs have traditionally existed to provide descriptions of items that the library owns and houses in a physical location. With the rise of remotely accessed Internet publications, catalogs have entered into an identity crisis. Some of our users are increasingly using Internet-based search engines and, depending on their respective subject fields, may prefer the convenience and timeliness of information gathered through this method over the more coherent organization and predictable retrieval of library catalogs.

A separation in the bibliographic universe is evolving, with items purchased in a physical carrier (whether print, CDROM, videocassette, etc.) in one file-the library catalog-and remotely accessed resources in another-the World Wide Web (Hillmann 1996). As libraries develop subject-based Web pages as tools for organizing and providing access to remote resources, some argue that it is redundant to include them in the library catalog. We would counter that the purpose of the library catalog must now be extended beyond the traditional inventory of physically held items to include remotely accessed items that have been selected by the subject bibliographer as appropriate for the particular collection. By providing a link to a given item on a Web page endorsed by the library, selectors are, in a very real sense, selecting that item and making it available by placing it on a virtual shelf. There follows from this a kind of "truth in advertising" principle: If a library takes steps to provide access to a resource, then it should also publicize to its clientele that it is available in the same way it does for other material, by including it in the catalog. We believe that in most cases if a library provides a Web link to an Internet publication, a corresponding catalog record should also be provided. The catalog record will, therefore, promote use of Internet resources by library constituents, thus maximizing the cost benefit to the institution.

Another benefit of including records for electronic journals in the library cata$\log$ is the prevention of unnecessary text procurement attempts, whether via interlibrary loan, document delivery, or per- 
sonal network, when, in fact, the library already "has" the item (i.e., is providing access to it). This will save money, time, and frustration for both the scholar and the library, thus improving everyone's productivity.

Users should be able to find remotely accessed items in the library catalog in the same way they find items held in physical formats. Mandel and Wolven have discussed Cutter's objectives for the catalog in light of the World Wide Web, cautioning us to "distinguish these goals from the traditional means used to achieve them" (Mandel and Wolven 1996, 30). Just as Cutter (1904) declared that the purpose of the catalog was to enable a person to find a book of which either the author, the title, or the subject is known, so should it enable a person to find an electronic publication of which any of those three attributes are known. Whereas Cutter's objectives focused on showing what the library has by a given author, on a given subject, or in a given kind of literature, we now must expand these objectives to include showing what the library has selected that meet these criteria.

While we advocate moving beyond a mentality of strict physical inventory, certainly those titles for which we pay subscription or license fees are the first choice to receive cataloging. Even if users are not yet accustomed to searching the online catalog for electronic journals, the library needs, for its own purposes, a reliable inventory of all titles for which it is expending funds. This is true whether the library has acted on its own or has shared the cost of a purchase through a consortium.

\section{Bibliographic RECORDS}

Although there are currently no procedural problems at Penn State with cataloging electronic titles, there are, of course, many complex issues involved in the actual content of the bibliographic record. Cataloging any item requires a series of decisions regarding treatment, description, main entry, added access points, and appropriate subject headings. Catalogers are guided in these decisions by the cataloging rules and other documentation. Because the bibliographic nature of serial publications is dynamic, serials catalogers must often make decisions for situations that are not covered explic. itly by cataloging rules, even for traditional print serials. Items published on the Internet pose even more challenging questions from the very beginning of the cataloging process. In order to make these cataloging decisions, Simpson worked closely with selectors as she began cataloging Internet resources.

The first question to be addressed when cataloging an Internet resource is, What is the work to be cataloged? In some cases this is readily apparent, as when we have subscribed to a straightforward journal whose publication pattern mimics closely that of a print publication, with a discrete title and clearly designated issues. In other cases, the resource might be embedded in a Web site of related material. Print publications arrive physically on the cataloger's desk, and while questions of treatment and access can occasionally require a conversation with a selector, usually it is clear from the beginning what is being cataloged. Internet publications by their very nature can be linked to other items and might not be organized into discrete bibliographic units. The selector might prefer that the bibliographic record point the user to the entire site rather than to a journal on the site. Catalogers cannot intuitively know how selectors envision a given resource will be used, nor can they tell by looking at a Web site which part of it users are likely to request by name. Selectors and catalogers must sit down and look at a site together in order to ensure that the cataloger understands what the selector is selecting.

Many of the electronic journals to which we subscribe are also available in print format on our shelves; thus a bibliographic record for the print version already resides in our online catalog. In this case, we must decide whether to catalog the electronic version separately or to in clude information about the electronic version on the record for the print version. The current CONSER policy requires separate records at the national level, but 
allows individual member institutions to use the one-record approach on an experimental basis in their local catalogs (Hirons 1997). While cataloging rules also require separate records for microfilm and print versions of the same item, Penn State, along with many other libraries, has elected to use one record when it has holdings in both print and microform formats. Some of the reasons that this approach is preferred for microfilm also apply to electronic formats. Catalog users are often confused by search results that include multiple records due to title changes, identical titles with uniform titles qualified by place, or similar titles for other serials and monographs.

It can be argued that adding another record to this mix only makes it harder for users to find what they are seeking. On the other hand, electronic versions of print resources are not strictly reproductions in the same sense that microfilm versions are. Even if an electronic product begins as an exact reproduction of the text of a print product, it usually isn't long before a publisher takes advantage of the inherent flexibility of the online environment by offering added features in the electronic version, such as revisions of articles, regularly updated newsletter sections, or even additional data not available in the print version. It is obviously problematic to consider such an enhanced electronic version to be the same work as the static print version. Some selectors at Penn State are more concerned that the user simply find an appropriate record and get to the resource than they are that we provide detailed, accurate descriptions; these selectors favor the one-record approach. Others feel strongly that the electronic version of a resource often differs from the print version enough that a separate record is essential in order to convey im. portant information about those differences to the user.

We have used both approaches in our catalog on a case-by-case basis, but generally we have preferred to catalog electronic resources separately for the following reasons. First, for acquisitions purposes we need a clearly distinguishable order record. Second, we do not yet have the ability to do automated checking of URLs, and it is easier to do manual maintenance if we can retrieve these records individually. But more importantly, in most cases our selectors have felt that separate records will meet the needs of users more completely. Including a note and a link for an electronic journal on the bibliographic record for the print journal may serve the purpose of leading a user to the electronic resource; but when this approach is used, it cannot be said that the electronic resource has been cataloged. The record describes only the print version and might be based on an issue that does not even exist in electronic form. Users can also be misled by the holdings statements for the print journal, which can differ from the electronic holdings. Often electronic versions of pre-existing print journals begin with the current year, and might or might not expand later to include earlier issues.

Despite the philosophical and practical difficulties of using one record for both paper and electronic versions, it seems clear that changes are needed in the approach we take to describing electronic publications. The Anglo-American Cataloguing Rules, $2 \mathrm{~d}$ ed. (AACR2), are based on the principle of describing the physical object in hand. Graham (1995) has adeptly described the problems of applying this principle to serials. It is not always easy to describe print serials adequately according to our current cataloging rules, due to the inherent difficulty of using one bibliographic record to describe many items (some or even most of which have yet to be published).

However, at least the issues of a printed serial that are in hand are not prone to change after they have been published. Publications that exist in electronic form might be changed at any time and in any number of ways. For instance, it is currently common for an electronic publication to require a special type of software reader, such as Adobe Acrobat, in order to display or print the file. Catalogers dutifully make a note that such software is required. It is entirely possible that in the near future some other, as yet not invented, reader will be required; how 
likely is it that the cataloger will be able to go back and change the notes on all of those records? And is it really necessary to alert the user to this characteristic in the bibliographic record when with a click of the mouse the user will view the resource itself, which in most cases will explain this on the first page and provide instructions for downloading the required software?

We suggest that this and other characteristics of electronic publications warrant a reexamination of the principle of in-depth description of an item. It would perhaps be more useful and efficient to consider briefer records, perhaps similar to those in the International Standard Serial Numbers (ISSN) network database. This database, compiled by approximately 65 national ISSN centers around the world, consists of records whose aim is to identify, rather than fully describe, serials as part of the process of assigning ISSN. Such brief records for Internet resources might be thought of as "access" records, leading users in an online environment directly to a resource, as opposed to an "ownership" or "inventory" record, describing a fixed object in enough detail to tell users whether or not it is worth their trouble to locate the physical object itself.

The questions raised here are being echoed in other forums as well. At the International Conference on the Principles and Future Development of AACR, held October 23-25, 1997, in Toronto, Ontario, Canada, Hirons and Graham (1997) highlighted many problems with the bibliographic control of serials in all formats and of continuing publications, paying particular attention to problems with the bibliographic control of electronic serials. As a result of their paper and the ensuing discussion, there are currently four CONSER task forces at work on revision of the rules for cataloging serials. While it is too soon to predict in detail the outcome of this endeavor, it is very likely that a new definition of serial will emerge-one that will include, for example, continuously updating databases. As publication patterns evolve and as the library community gains more ex- perience with electronic journals, we can expect standards for their bibliographic control to continue to change as well. Whatever the exact form of these standards, librarians must continue the process of selecting and providing access to these materials. The challenges we face in this endeavor will be met much more effectively if selectors, reference librarians, and catalogers work closely together to integrate these materials into our collections and our catalogs.

\section{Works Cited}

Association of Research Libraries (ARL). 1996. Electronic publishing explodes on the Web. ARL 187: 6 .

1998. ARL announces... seventh edition of the Directory of Electronic Journals, Newsletters and Academic Discussion Lists. Available at: http://wwwarl. org/scomm/edir/pr97.html.

Avery, Chris. 1996. Focus group results. Interoffice Penn State University memo to Gloriana St. Clair. Dec. 16.

Cutter, Charles Ammi. 1904. Rules for a dictionary catalog: selections. In Foundations of Cataloging, ed. Michael Carpenter and Elaine Svenonius. Littleton, Colo: Libraries Unlimited, 1985.

Graham, Crystal. 1995. What's wrong with AACR2: A serials perspective. In The Future of the Descriptive Cataloging Rules, ed. Brian E. C. Schottlaender. Chicago: American Library Association.

Hillmann, Diane I. 1996. "Parallel universes" or meaningful relationships: Envisioning a future for the OPAC and the Net. Cataloging \& classification quarterly 22, nos. 3/4: 97-103.

Hirons, Jean L. 1997. One record or two? The online discussion and the CONSER interim approach. Journal of Internet cataloging 1, no. 2: 3-14.

Hirons, Jean L., and Crystal Graham. 1997. Issues related to seriality. Paper presented at the International Conference on the Principles and Future Development of AACR, Toronto, Ontario, October 23. Available at: http://www. nlc-bnc.ca/jsc/ r-serial.pdf.

Mandel, Carol A., and Robert Wolven. 1996. Intellectual access to digital documents: Joining proven principles with new technologies. Cataloging \& classification quarterly 22 , nos. 3/4: 25-42. 